\title{
IL-33-induced JNK pathway activation confers gastric cancer chemotherapy resistance
}

\author{
XIAO-LEI YE ${ }^{1,3^{*}}$, YA-RONG ZHAO ${ }^{1,2^{*}}$, GUO-BIN WENG $^{1}$, YI-CHEN CHEN ${ }^{2}$, \\ XUE-NI WEI ${ }^{1,2}$, JING-PING SHAO ${ }^{3}$ and $\mathrm{HUI} \mathrm{JI}^{2}$ \\ ${ }^{1}$ Cancer Institute, Yinzhou People's Hospital, Ningbo, Zhejiang 315020; ${ }^{2}$ School of Pharmacy, \\ China Pharmaceutical University, Nanjing, Jiangsu 210009; ${ }^{3}$ Division of Drugs and Pharmacology, \\ Ningbo Institute of Medical Sciences, Ningbo, Zhejiang 315020, P.R. China
}

Received September 9, 2014; Accepted December 15, 2014

DOI: $10.3892 /$ or.2015.3898

\begin{abstract}
Inflammation is regarded as one of the major hallmarks of tumors, and has a very close relationship with gastric cancer. Interleukin-33 (IL-33), a new member of the IL-1 family, plays an important role in both inflammatory disease and tumors. The present study was designed to explore the effects of IL-33 on the proliferation, drug sensitivity, and the invasiveness of gastric cancer cells in vitro. IL-33 at concentrations lower than $100 \mathrm{pg} / \mathrm{ml}$ did not alter the inhibitory rate of gastric cancer cells. Moreover, IL-33 at these low concentrations protected against platinum-induced apoptosis in various gastric cancer cell lines, yet not in normal gastric epithelial cells. We also found that IL-33 increased the activation of the JNK pathway, and enhanced the expression of ST2. Furthermore, SP600125, a selective inhibitor of the JNK pathway, significantly blocked the protective effects of IL-33 in gastric cancer cells. In addition, Matrigel invasion assay showed that IL-33 markedly promoted gastric cancer cell invasion. In conclusion, the present study demonstrated that IL-33 protected against platinum-induced apoptosis and promoted cell invasion via activation of the JNK pathway in gastric cancer cells. In light of the prevalence of platinumbased chemotherapeutics in the treatment of gastric cancer, our results suggest that the level of IL-33 should be monitored during the treatment of gastric cancer, particularly when using platinum-based chemotherapeutics.
\end{abstract}

Correspondence to: Professor Guo-Bin Weng, Cancer Institute, Yinzhou People's Hospital, Ningbo, Zhejiang 315020, P.R. China E-mail:wgb@nbyzyy.com

Professor Hui Ji, Pharmacology, School of Pharmacy, China Pharmaceutical University, Nanjing, Jiangsu 210009, P.R. China E-mail: huijicpu@163.com

*Contributed equally

Key words: IL-33, gastric cancer, apoptosis, invasion

\section{Introduction}

Gastric cancer is one of the most common types of cancers. Over 1.6 million individuals succumb to gastric cancer each year in China. The Chinese incidence of gastric cancer accounts for more than $40 \%$ of the worldwide occurrences. Moreover, the progression-free survival and overall survival rates of gastric cancer patients in China are much lower than those in Europe and the US. Therefore, research concerning the characteristics and pathogenesis of gastric cancer in Chinese patients is urgently needed.

Gastric cancer can be influenced by a wide range of genetic and environmental factors. A clear association has been reported between gastric cancer and chronic inflammation (1-3). Pro-inflammatory factors, including interleukin-1 (IL-1), IL-6 and tumor necrosis factor (TNF), may not only play roles in inflammation-associated carcinogenesis (4), but may also influence the chemotherapeutic sensitivity during gastric cancer treatment $(5,6)$. IL-33 (previously known as NF-HEV), an 18-kDa protein, is a new member of the IL-1 family (7). Traditionally, the IL-1 family is well known for their effects on host defense, immune regulation and inflammation (7). However, recent research suggests that the IL-1 family is also involved in cancer development. For example IL-18, another member of the IL-1 family, acts as a pleiotropic cytokine in many types of cancer cells, and influences the invasion of gastric cancer cells under hypoxia (8). A high level of IL-18 in serum has been intensively associated with a wide variety of tumors, such as hepatocellular (9) and esophageal carcinoma (10) and gastric cancer (11).

The structures of IL-33 and IL-18 are very similar. Therefore, it is believed that IL-33 and IL-18 may have similar biological functions related to cancer development (12). Actually, IL-33 is abundantly expressed in the nuclei of endothelial cells in human tumor tissues, such as in kidney, stomach, liver and pancreas tissues (13). The serum level of IL-33 (14) was found to be significantly increased ( 6-fold) in gastric cancer patients, and a higher serum level of IL-33 in gastric cancer patients was found to correlate with poor prognosis.

However, the relationship between IL-33 and the development of gastric cancer is largely unknown. In the present study, 
the effects and the underlying mechanisms of IL-33 in regards to the proliferation and drug sensitivity of gastric cancer were explored.

\section{Materials and methods}

3-(4,5-Dimethylthiazol-2-yl)-2,5-diphenyltetrazolium bromide (MTT) assay. The proliferation level of cells was detected by MTT (Invitrogen, USA) assay as described below. GES-1 cells and a gastric cancer cell line (SIBCB, Shanghai, China) were grown in RPMI-1640 (Gibco, USA) supplemented with 10\% fetal bovine serum (FBS) (Biological Industries, Israel). The cells were trypsinized and grown in a 96 -well plate (Corning Incorporated, USA) at a density of $1 \times 10^{5} /$ well and incubated for $24 \mathrm{~h}$ at $37^{\circ} \mathrm{C}$, in $5 \% \mathrm{CO}_{2}$. IL-33 (Sigma, USA) at a final concentration of $7.8,15.6,31.25,62.5,125,250,500$ and $1,000 \mathrm{pg} / \mathrm{ml}$ was incubated with MGC803 and GES-1 cells, respectively for $24 \mathrm{~h}$. Twenty microliters MTT $(5 \mathrm{mg} / \mathrm{ml})$ was added into the cells and incubated for $4 \mathrm{~h}$. After removing the supernatant, $200 \mu \mathrm{l}$ DMSO was added to dissolve the formazan. The absorbance value (OD) was detected at a 570-nm wavelength with a microplate reader (Thermo, USA), with $630 \mathrm{~nm}$ as reference. The cell viability $(\%)=$ treatment group OD/control group OD. The experiment was repeated three times. For the cell protection assay, MGC803 cells were incubated with 5-FU, adriamycin, cis-platinum (DDP) and etoposide (Sigma) coupled with 0, 20, 40, 60, 80 pg/ml IL-33. All of these chemotherapy drugs were at the concentration of $10 \mu \mathrm{M}$. After incubation with the MGC803 cells for $24 \mathrm{~h}$, MTT assay was carried out and the inhibition rate was calculated. The inhibition rate $(\%)=(1-$ treatment group OD/control group OD) x $100 \%$. For evaluation of the protective effects against DDP-induced cell inhibition, GES-1 and gastric cancer cell lines MGC803, SGC7901 and GC9811-P were incubated with $0,5,10,20 \mu \mathrm{M}$ DDP coupled with $60 \mathrm{pg} / \mathrm{ml} \mathrm{IL-33} \mathrm{for}$ $24 \mathrm{~h}$. Then MTT assays were carried out as described above.

Flow cytometric analysis. MGC803 cells were cultured in RPMI-1640 supplemented with $10 \%$ FBS. The cells were incubated with DDP $(10 \mu \mathrm{M})$ and a triple-drug combination (TDC) [5-FU, oxaliplatin (Sigma); docetaxel; 750:75:75 $\mu \mathrm{g} / \mathrm{ml}$ (15)] alone or with $60 \mathrm{pg} / \mathrm{ml} \mathrm{IL-33} \mathrm{for} 24 \mathrm{~h}$, and the apoptosis assay was performed with an Annexin V/PI staining kit (Bender MedSystems, USA). The experiment was carried out according to the instruction manual provided in the kit. After staining, the cells were analyzed by flow cytometry (Calibur; BD, USA), and data were collected and analyzed using FlowJo software (version 10.0). The experiment was repeated three times.

Western blotting. Levels of activated-PARP, ST2, and MAPK pathway-related proteins including p-ERK1/2, P38, p-JNK were determined as described below. Confluent cultured MGC803 cells were treated with different concentrations of the compounds including $10 \mu \mathrm{M}$ DDP or TDC alone or with $60 \mathrm{pg} / \mathrm{ml} \mathrm{IL-33} \mathrm{for} 24 \mathrm{~h}$. The cell lysates containing $25 \mu \mathrm{g}$ protein were electrophoresed on polyacrylamide gel in the presence of sodium dodecyl sulfate-polyacrylamide gel electrophoresis (SDS-PAGE) and electroblotted to a polyvinylidene fluoride (PVDF) membrane (Millipore Corporation, USA). After blocking with non-fat milk, the



Figure 1. The function of IL-33 on the proliferation of GES-1 and MGC803 cells. MGC803 and GES-1 cells were incubated with 7.8, 15.6, 31.25, 62.5 $125,250,500$ and $1,000 \mathrm{pg} / \mathrm{ml}$ IL-33 alone for $24 \mathrm{~h}$. The cell viability rate (\%) is expressed as the mean \pm SD from three independent experiments.

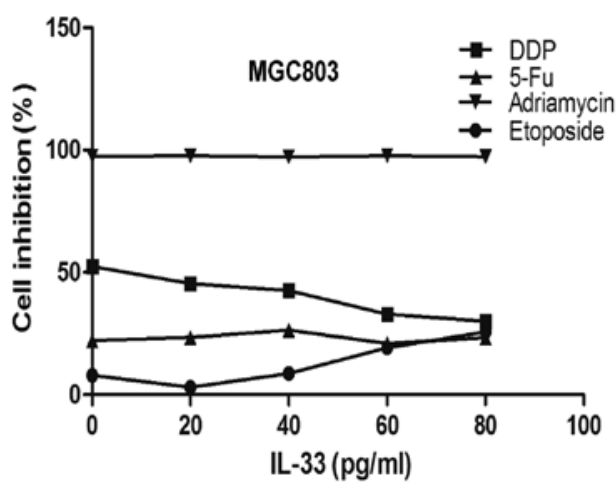

Figure 2. Effect of chemotherapeutics coupled with IL-33 on MGC803 cells. MGC803 cells were incubated with 5-FU $(10 \mu \mathrm{M})$, adriamycin, DDP and etoposide coupled with $0,20,40,60$ and $80 \mathrm{pg} / \mathrm{ml}$ IL-33 for $24 \mathrm{~h}$. The cell inhibition rate $(\%)$ is expressed as the mean \pm SD from three independent experiments.

PVDF membrane was incubated with the primary antibodies (Cell Signaling Technology, USA) overnight at $4^{\circ} \mathrm{C}$. Then the secondary antibody (Cell Signaling Technology) was added and after washing with TBS-T buffer, the PVDF membrane was visualized using ECL chemiluminescence (Invitrogen) and exposed to X-ray film (Kodak, USA). The bands were quantified by ImageJ (version 1.47) with $\beta$-tubulin (Cell Signaling Technology) as the internal reference. The experiment was repeated three times.

JNK inhibition assay. MGC803 cells were trypsinized and grown in 96-well plates at the density of $10^{5}$ cells/well. After pretreatment with $10 \mu \mathrm{M}$ of SP600125 (Calbiochem, USA), a highly selective JNK inhibitor for $1 \mathrm{~h}$, the MGC803 cells was incubated with $10 \mu \mathrm{M}$ DDP and TDC alone or with $60 \mathrm{pg} / \mathrm{ml}$ IL-33 for $24 \mathrm{~h}$. Then the cell inhibition rate was detected by MTT assay. The experiment was repeated three times.

Matrigel invasion assay. Twenty-four-well plates with an inner chamber was chosen for the invasion assay, and membranes with an $8-\mu \mathrm{m}$ pore size were precoated with $10 \mu \mathrm{g} / \mathrm{ml}$ Matrigel (Corning Incorporated). The MGC803 cells were trypsinized and grown on the inner chamber at the density of $1 \times 10^{6}$ cells/well 


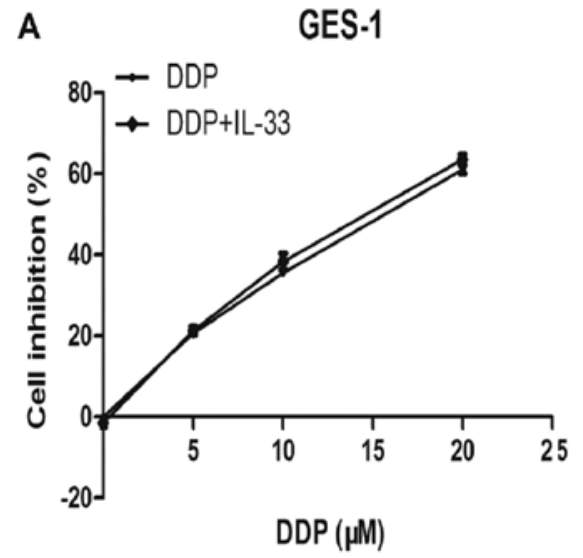

C

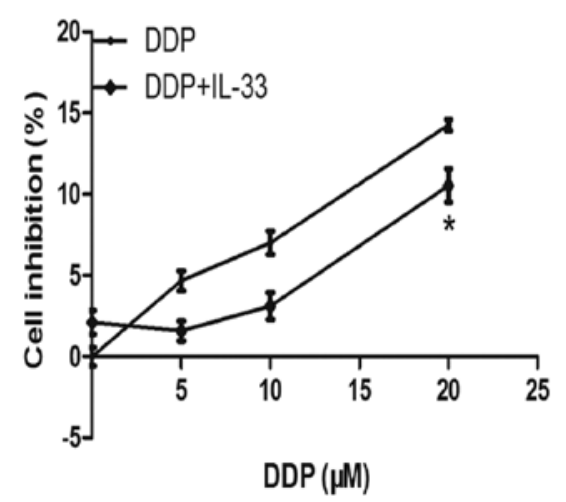

B

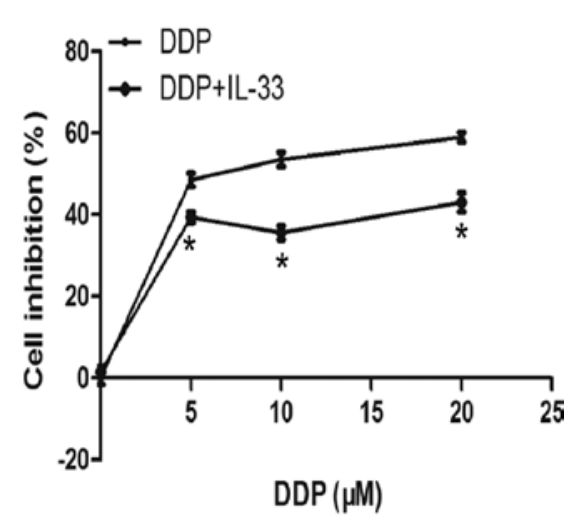

D

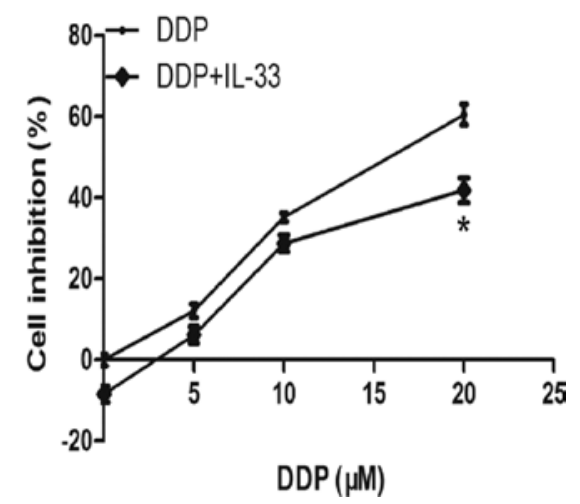

Figure 3. Effect of DDP coupled with IL-33 on gastric cancer and GES-1 cells. (A) GES-1 cells and gastric cancer cell lines (B) MGC803, (C) SGC7901, (D) GC9811-P were incubated with cis-platinum (DDP) $(0,5,10,20 \mu \mathrm{M})$ combined with $60 \mathrm{pg} / \mathrm{ml} \mathrm{IL-33} \mathrm{for} 24 \mathrm{~h}$. The cell inhibition rate (\%) is expressed as the mean \pm SD from three independent experiments. ${ }^{*} \mathrm{p}<0.05$.

in RPMI-1640, with RPMI-1640 medium containing 0, 30, 60 and $120 \mathrm{pg} / \mathrm{ml}$ IL-33 in the lower chamber separately. In addition, the positive control was performed with RPMI-1640 containing $10 \%$ FBS in one lower chamber and MGC803 cells in RPMI-1640 medium in the upper chamber. After incubation at $37^{\circ} \mathrm{C}$ for $6 \mathrm{~h}$, cells on the upper surface of the filter were removed and cells adhering to the undersurface of the filter membrane were dyed with $0.5 \%$ crystal violet for $30 \mathrm{~min}$. The crystal violet was washed with PBS for three times. Cells on the lower chamber were counted under a microscope in four fields randomly. The mean cell numbers were recorded and analyzed. The experiment was repeated three times.

Statistical analysis. The differences were analyzed by the two-tailed Student's t-test using SPSS 13.0. Statistical significance was verified at $\mathrm{p}<0.05$. The graphs were constructed using GraphPad Prism for Windows (version 5.0).

\section{Results}

Proliferative effect of IL-33 alone on gastric cancer and normal epithelial cells. To explore the direct influence of IL-33 on the proliferation of GES-1 and gastric cancer cells, GES-1 and MGC803 cells were incubated with different concentrations of IL-33 for $24 \mathrm{~h}$. As shown in Fig. 1, IL-33 inhibited the proliferation of GES-1 cells slightly and stimulated the proliferation of MGC803 mildly. This implied that IL-33 nearly had no obvious effects on the proliferation of both cell lines at a low concentration $(<100 \mathrm{pg} / \mathrm{ml})$. Thus, IL-33 at a lower concentration was chosen for the subsequent experiments.

IL-33 protects gastric cancer MGC803 cells from apoptosis induced by a platinum drug. In the present study, the effect on proliferation of different chemical compounds on MGC803 cells were assessed when co-cultured with IL-33. MGC803 cells were incubated with 5-FU, adriamycin, DDP and etoposide at the concentration of $10 \mu \mathrm{M}$ coupled with $0,20,40,60$ and $80 \mathrm{pg} / \mathrm{ml}$ IL-33. As shown in Fig. 2, IL-33 at $60 \mathrm{pg} / \mathrm{ml}$ significantly reduced the apoptosis caused by DDP but not with the other chemical compounds $(\mathrm{p}<0.05)$.

After the above experiment, GES-1 and gastric cancer cell lines MGC803, SGC7901 and GC9811-P were cultured with 0, 5, 10 and $20 \mu \mathrm{M}$ DDP coupled with $60 \mathrm{pg} / \mathrm{ml}$ IL-33 for $24 \mathrm{~h}$. As shown in Fig. 3, the MTT assay data revealed that IL-33 decreased the inhibitory rate of DDP in the gastric cancer cells, particularly in the MGC803 cells. This implies that IL-33 protects MGC803 and other gastric cancer cells from apoptosis induced by DDP. Yet, it had no apparent proliferative effect on GES-1 cells. The protective effect on cell proliferation was more obvious in the MGC803 cells at 5, 10 and $20 \mu \mathrm{M}$ DDP with statistical significance $(\mathrm{p}<0.05)$, and MGC803 cells were chosen for use in the following experiments.

Furthermore, a flow cytometric assay was carried out to confirm the above result. Considering the significance of 

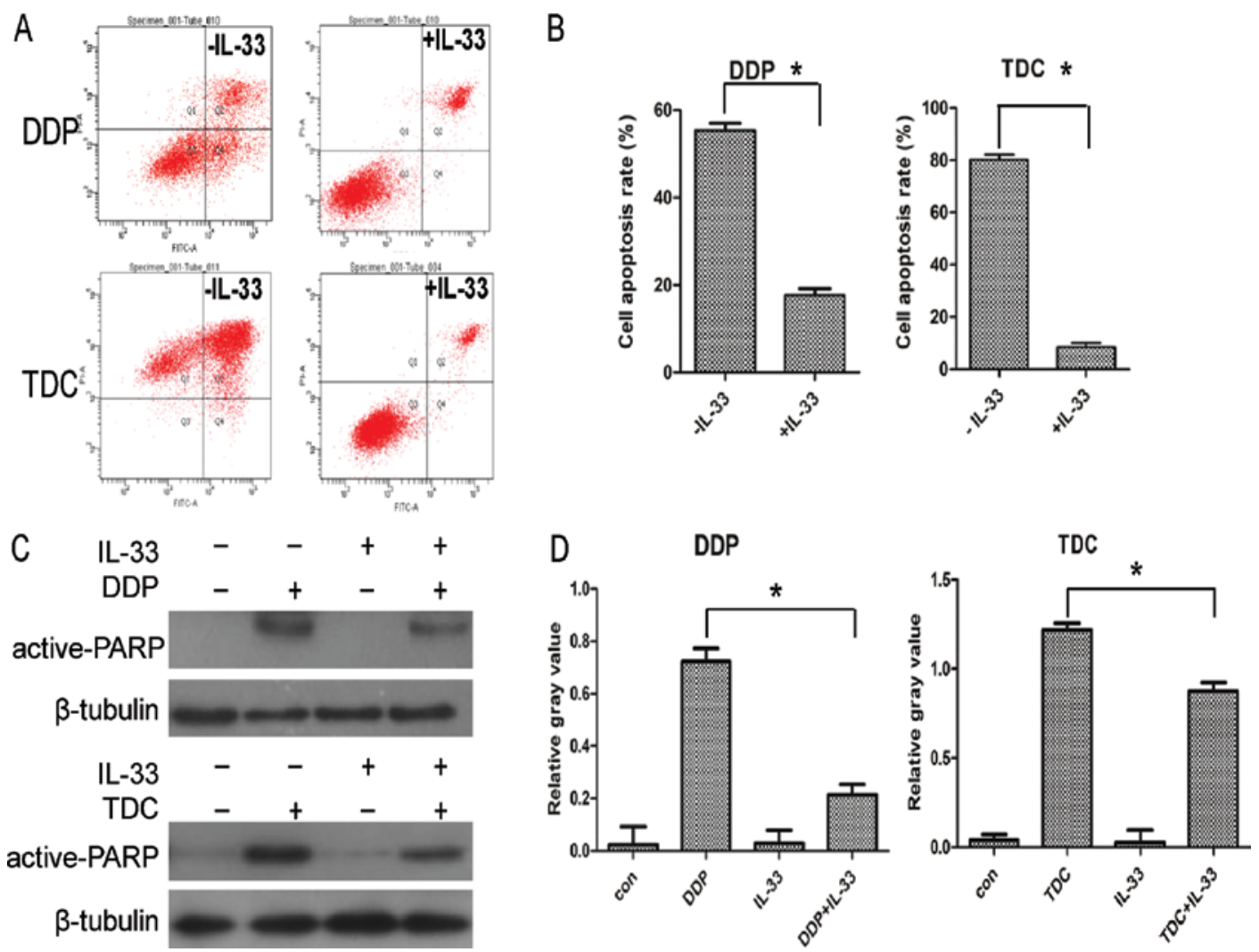

Figure 4. IL-33 protects MGC803 cells from apoptosis induced by platinum-based drugs. (A) MGC803 cells were incubated with DDP and TDC containing oxaliplatin alone and with $60 \mathrm{pg} / \mathrm{ml}$ IL-33 for $24 \mathrm{~h}$. Cells were collected for flow cytometry. (B) The apoptosis rate is expressed as the mean \pm SD from three independent experiments. " $\mathrm{p}<0.05$. (C) After the MGC803 cells were treated with DDP and/or IL-33 for $24 \mathrm{~h}$, the protein level of active-PARP was detected by western blotting. After MGC803 cells were treated with TDC and/or IL-33 for $24 \mathrm{~h}$, the protein level of active-PARP was detected by western blotting. (D) The expression of active-PARP was quantified and normalized to $\beta$-tubulin, and is presented as the mean \pm SD from three independent experiments. ${ }^{*}<<0.05$.

combination drug therapy, apart from DDP, MGC803 cells were incubated with TDC containing oxaliplatin alone or with $60 \mathrm{pg} / \mathrm{ml} \mathrm{IL}-33$. As shown in Fig. 4A and B, when coupled with IL-33, the apoptosis rate of the MGC803 cells declined markedly, and the phenomenon was more obvious in the TDC treatment group. In addition, as shown in Fig. $4 \mathrm{C}$ and D, expression of apoptosis protein active-PARP was decreased compared to the level in the control group when cultured with IL-33; all of the above data confirmed that IL-33 protects MGC803 cells from apoptosis induced by DDP or platinum-based cytotoxic drugs.

Expression of ST2 in the MGC803 cells. MGC803 cells were treated with DDP or TDC and IL-33 for $24 \mathrm{~h}$, and the protein level of ST2 was detected by western blotting. As shown in Fig. 5A and B, compared with the untreated group, the protein expression of ST2 was slightly increased following treatment with DDP, TDC or IL-33 alone. When MGC803 cells were treated with both DDP or TDC and IL-33, expression of ST2 was obviously increased compared to the DDP or TDC group.

IL-33 may have protective a function via the JNK pathway. The mechanism of IL-33 was explored by western blotting. MGC803 cells were treated with DDP or TDC alone and with IL-33 for 24 h. Phospho-MAPK (ERK1/2, p38, JNK) protein expression was detected. As shown in Fig. 5C and D, the p38 protein level had almost no change, yet phospho-ERK1/2 increased slightly and expression of phospho-JNK (p-JNK) obviously increased when the cells were incubated with IL-33. The result showed that when the cells were treated with both DDP or TDC and $60 \mathrm{pg} / \mathrm{ml} \mathrm{IL-33,} \mathrm{phospho-ERK1/2} \mathrm{was}$ increased slightly, and p-JNK was increased obviously. IL-33 may play a protective function through JNK pathway activation, and partially through treatment with ERK1/2.

Following treatment with the JNK inhibitor, MTT assay was carried to assess cell growth. MGC803 cells were incubated with DDP, TDC and IL-33 alone and/or with JNK inhibitor pretreatment for $1 \mathrm{~h}$. As shown in Fig. 5E and F, compared with the inhibitor non-treatment group, the cell viability was obviously decreased when cultured with the JNK inhibitor. This phenomenon was more obvious in the TDC group and the data reached statistical significance compared to the control group $(\mathrm{p}<0.05)$. These data indicate that JNK plays an important role in the IL-33 protective function.

IL-33 stimulates the invasive ability of the gastric cancer MGC803 cells. In addition to the proliferation function of IL-33, the influence of IL-33 on cell invasion was explored via a Matrigel invasion assay. As shown in Fig. 6, following treatment with a higher concentration of IL-33, the number of invasive cells was increased. The invasion data indicated that IL-33 promoted MGC803 cell invasion, and the data reached statistical significance compared to the control group $(\mathrm{p}<0.05)$. Thus IL-33 may be an inducible factor of gastric cell invasion, and even may promote the metastasis of gastric cancer. 


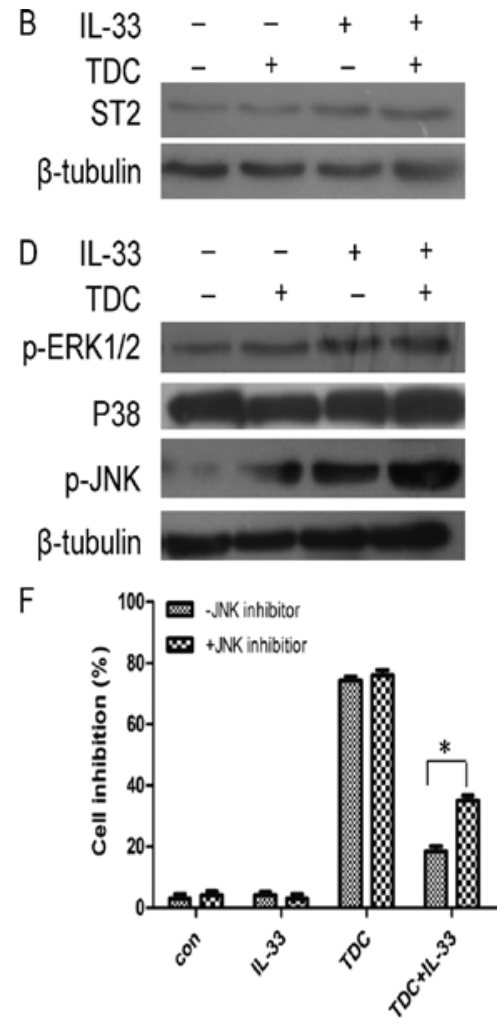

Figure 5. ST2 and JNK pathway in IL-33 function. (A) MGC803 cells were treated with DDP and/or IL-33 for $24 \mathrm{~h}$, and the protein level of ST2 was detected by western blotting. (B) MGC803 cells were treated with TDC and/or IL-33 for $24 \mathrm{~h}$, and the protein level of ST2 was detected by western blotting. (C) Expression levels of p-ERK1/2, p38 and p-JNK were detected by western blotting. Activation of ERK1/2 and JNK is shown. (D) Expression levels of p-ERK1/2, p38 and p-JNK were detected by western blotting. Activation of ERK1/2 and JNK is shown. (E) DDP $(10 \mu \mathrm{M})$ combined with IL-33 (60 pg/ml), and/or the JNK inhibitor were incubated with the MGC803 cells. The cell inhibition rate is expressed as the mean \pm SD from three independent experiments. " $\mathrm{p}<0.05$. (F) TDC, IL-33 and JNK inhibitor were incubated with MGC803 cells. The cell inhibition rate is expressed as the mean \pm SD from three independent experiments. "p<0.05.

A



$\mathrm{IL}-33(\mathrm{pg} / \mathrm{ml})$

$$
30
$$

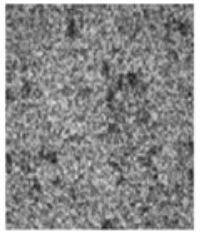

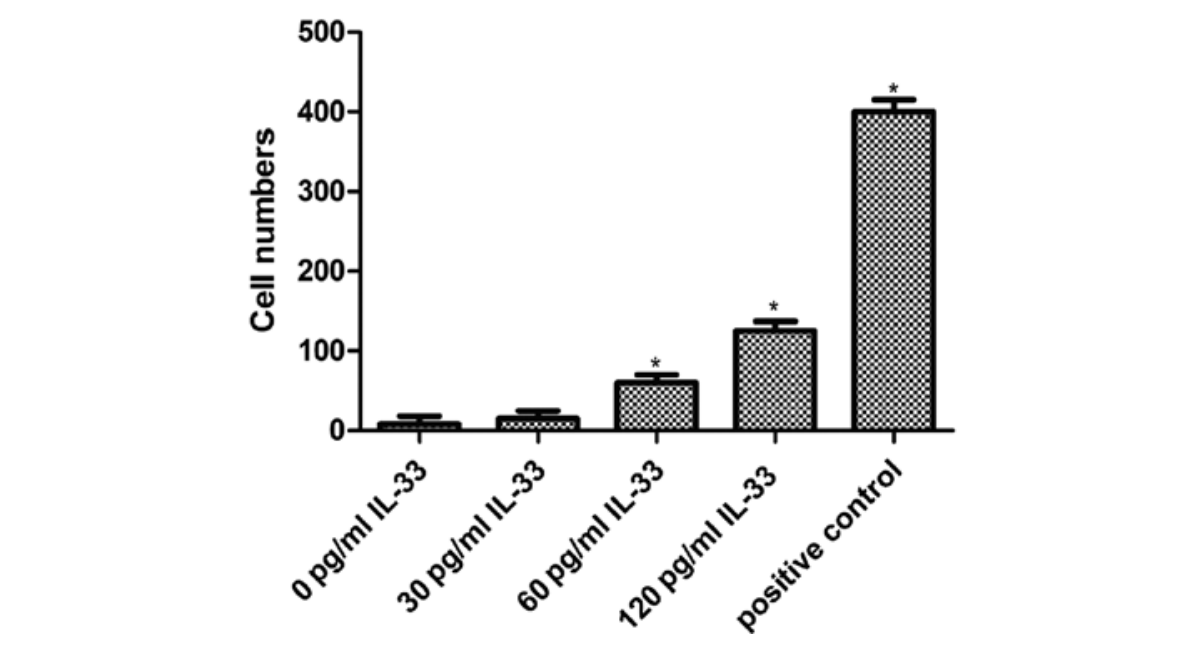

positive control

\section{0}


B

Figure 6. IL-33 promotes the invasive potential of MGC 803 cells. (A) Effects of IL-33 on cell invasion by Matrigel invasion assays. Representative images of invaded cells are shown. Scale bar, $50 \mu \mathrm{m}$. Upper chambers contained RPMI-1640 and lower chambers contained RPMI-1640 with IL-33. The positive control was performed with RPMI-1640 medium containing $10 \%$ FBS in the lower chamber. The cells were stained with $0.5 \%$ crystal violet. (B) Invaded cells were counted and the results are expressed as the mean \pm SD from three independent experiments. " $p<0.05$. 


\section{Discussion}

As a new member of the IL-1 family, research on IL-33 has been mainly focused on inflammation. For example, IL-33 at $10-100 \mathrm{ng} / \mathrm{ml}$ significantly and dose-dependently enhanced the survival of eosinophils (16), and IL-33 promoted the proliferation of circulating fibrocytes in patients with allergen-exacerbated asthma (17). In the present study, the proliferative effect of IL-33 on gastric cancer cells was firstly reported. Gastric cancer MGC803 cells and normal gastric epithelial GES-1 cells were incubated with IL-33 at 7.8-1,000 pg/ml. Notably, IL-33 at a low concentration $(<100 \mathrm{pg} / \mathrm{ml})$ had no obvious proliferative effect on the GES-1 and MGC803 cells. This avoided an individual effect of IL-33 on cell proliferation in the following experiments.

In the present study, IL-33 decreased the apoptosis rate of chemotherapeutic compounds in gastric cancer cell lines, yet not in normal epithelial GES-1 cells. At present, fluoropyrimidine, taxanes and platinum-based regimens are most frequently used and offer a response rate of 30-50\% with a median overall survival of $\leq 1$ year (18). Considering the combined usage in the clinic, apart from DDP, TDC containing oxaliplatin was applied. PARP-1 activation has been shown to cause cell death by triggering a signaling cascade involving the MAP kinase JNK (19). In the present study, the apoptosis of cells was confirmed by MTT assay, flow cytometry and the protein active-PARP level. MTT data showed that among 5-FU, adriamycin, DDP and etoposide, IL-33 reduced the apoptosis caused by DDP in three gastric cancer cell lines yet not in GES-1 cells. In addition, IL-33 was found to weaken the apoptotic effect induced by TDC, consistent with the DDP group. The present study clearly showed that IL-33 reduced the cytotoxic effect of the chemotherapeutics on the gastric cancer cell lines, particularly for the platinum-based therapy. However, IL-33 had no apparent effect on the apoptosis of GES-1 cells induced by DDP, which imply that IL-33 may selectively protect gastric cancer cells from apoptosis rather than normal cells. Similarly, there is another interleukin that has a similar protective function as IL-33. IL-22 protects colorectal cancer cells from chemotherapy by activating the STAT3 pathway (20). The results further imply that IL-33 may weaken the therapeutic effect of platinum-based chemotherapeutics in gastric cancer.

Among the IL-1 family, ST2 was identified as an IL-33 receptor (7). In the present study, the ST2 protein level was increased compared to the control group after chemotherapy, and increased further when incubated with both chemotherapeutic agents and IL-33 in MGC803 cells. This implied that expression of ST2 was increased after cell apoptosis induced by DDP and TDC. It has been reported that SST2 is associated with liver injury and cell death as well as systemic inflammatory response (21). Following co-culture with IL-33, ST2 was induced compared to the DDP or TDC group, indicating that IL-33 induced the expression of ST2. Research has shown that activation or recruitment of IL-33 in target cells co-expressing the ST2 receptor led to increased ST2 levels in serum (13). However, extracellular IL-33 was found to promote the expression of ST2 in gastric cancer. The present study implied that apart from inflammation, the IL-33/ST2 pathway affects the cell proliferation and drug sensitivity in gastric cancer.

As found in a previous study, IL-33 was able to bind a heterodimeric receptor complex consisting of ST2 and
IL-1R accessory protein (IL-1 RAP) (22) and to activate NK- $\mathrm{BB}$ and mitogen-activated protein kinases (MAPKs) (23). MAPK pathways involve the extracellular signal-regulated kinases: ERK1/2, c-Jun amino-terminal kinase JNK and p38 kinase (24). Recent data suggest that MAPKs may mediate apoptotic signaling induced by anticancer drugs (25). For example, sustained activation of JNK/p38 MAPK in response to cisplatin was found to lead to cell death in ovarian carcinoma cells (26). JNK was found to be activated in response to chemical and environmental stress and to inflammatory cytokines (27). Research also suggests that regulation of the ERK1/2 and P38 MAPK signaling pathways is crucial in the context of DNA-damaging drug-induced apoptosis and may be generally involved in the apoptosis induced by anticancer DNA-damaging drugs, including doxorubicin and etoposide (28). In the present study, to reveal the protective mechanism of IL-33 in gastric cancer, the MAPK pathway including ERK1/2, P38, JNK was detected via western blotting. The data revealed that ERK1/2 and JNK were activated through phosphorylation under the condition of IL-33, while JNK activation was more obvious, which indicated that JNK has a significant correlation with IL-33. Thus, we conclude that JNK plays an important role in the IL-33 protective function, as well as ERK1/2. Considering that IL-33 could promote the expression of ST2, we conclude that IL-33 may function via the IL-33/ST2 and MAPK pathways including JNK and ERK1/2.

To confirm these findings, MTT assay following treatment with the JNK inhibitor was carried out. Consistent with the present study, the cell inhibition rate was higher following treatment with the JNK inhibitor, which implied that the JNK inhibitor blocked the protective effects of IL-33 in gastric cancer cells. Thus, JNK may be a key factor in the IL-33 function for protecting gastric cancer cells from apoptosis. Other studies have shown the significance of JNK in gastric cancer. For example, IL-18-enhanced thrombospondin expression was blocked by the JNK-specific inhibitor (SP600125) and it enhanced the expression of phosphorylated JNK in human gastric cancer cell lines (29). Diversin increased the proliferative and invasive ability of non-small cell lung cancer cells via the JNK pathway (30).

Many inflammatory cytokines have influence on cell proliferation, as well as on cell migration. According to a previous study, IL-1 $\beta$, besides its central role in inflammation, has also been recognized as a factor affecting tumor progression, angiogenesis and invasiveness (31). In the Matrigel invasion assay, we explored the function of IL-33 in MGC803 cell invasion. The results showed that IL-33 could promote MGC803 cell invasion. The data revealed that IL-33 may accelerate gastric cell invasion and may be an alarm for gastric cancer. Considering the results above, IL-33 may indicate the poor prognosis of gastric cancer patients particularly those with a high IL-33 level in the serum (14). In addition, a high level of IL-33 was found to be a poor prognostic factor in other tumors. For example, overexpression in head and neck squamous cell carcinoma was found to promote migration and invasion (32). IL-33 accelerated breast cancer growth and metastasis through increased intratumoral accumulation of immunosuppressive cells and diminished innate antitumor immunity. The above function was attenuated in the absence of ST2 (33). In short, a high IL-33 level may be detrimental to the tumor and should be treated as an alarm during therapy. 
The present study demonstrated that IL-33 protected gastric cancer cell lines rather than normal gastric epithelial GES-1 cells from apoptosis induced by chemical compounds containing platinum. In addition, the protective function of IL-33 in gastric cancer cell apoptosis was mainly through the JNK pathway. IL-33 stimulated gastric cancer cell invasion. The results imply that IL-33 may combine with ST2 to affect platinum therapy in gastric cancer and even worsen the disease. In the clinical therapy of gastric cancer, evaluation of the serum level of IL-33 before drug administration is recommended. If patients have a high IL-33 serum level, then chemotherapeutics containing platinum should be avoided or applied cautiously. In addition, various specific molecular inhibitors can be combined with platinum therapy, such as a JNK inhibitor. Further in vivo and clinical research of IL-33, particularly in regards to gastric cancer patients is warranted.

\section{Acknowledgements}

This study was funded by Ningbo Natural Science Foundation (no. 2011A610048)

\section{References}

1. Oguma $\mathrm{K}$, Oshima $\mathrm{H}$ and Oshima M: Inflammation, tumor necrosis factor and Wnt promotion in gastric cancer development. Future Oncol 6: 515-526, 2010.

2. Ernst P: Review article: the role of inflammation in the pathogenesis of gastric cancer. Aliment Pharmacol Ther 13 (Suppl 1): S13-S18, 1999.

3. Fox JG and Wang TC: Inflammation, atrophy, and gastric cancer. J Clin Invest 117: 60-69, 2007.

4. Multhoff G, Molls M and Radons J: Chronic inflammation in cancer development. Front Immunol 2: 98, 2012.

5. Mosaffa F, Kalalinia F, Lage H, Afshari JT and Behravan J: Pro-inflammatory cytokines interleukin-1 beta, interleukin 6 , and tumor necrosis factor-alpha alter the expression and function of ABCG2 in cervix and gastric cancer cells. Mol Cell Biochem 363: 385-393, 2012.

6. Chen CC, Chu CB, Liu KJ, Huang CY, Chang JY, Pan WY, Chen HH, Cheng YH, Lee KD, Chen MF, et al: Gene expression profiling for analysis acquired oxaliplatin resistant factors in human gastric carcinoma TSGH-S3 cells: the role of IL-6 signaling and Nrf2/AKR1C axis identification. Biochem Pharmacol 86: 872-887, 2013.

7. Schmitz J, Owyang A, Oldham E, Song Y, Murphy E, McClanahan TK, Zurawski G, Moshrefi M, Qin J, Li X, et al: IL-33, an interleukin-1-like cytokine that signals via the IL-1 receptor-related protein ST2 and induces T helper type 2-associated cytokines. Immunity 23: 479-490, 2005.

8. Shen Z, Seppänen H, Vainionpää S, Ye Y, Wang S, Mustonen H and Puolakkainen P: IL10, IL11, IL18 are differently expressed in $\mathrm{CD}_{14}{ }^{+} \mathrm{TAMs}$ and play different role in regulating the invasion of gastric cancer cells under hypoxia. Cytokine 59: 352-357, 2012.

9. Mohran ZY, Ali-Eldin FA and Abdel Aal HA: Serum interleukin-18: does it have a role in the diagnosis of hepatitis $C$ virus related hepatocellular carcinoma? Arab J Gastroenterol 12: 29-33, 2011.

10. Tsuboi K, Miyazaki T, Nakajima M, Fukai Y, Masuda N, Manda R, Fukuchi M, Kato H and Kuwano H: Serum interleukin-12 and interleukin-18 levels as a tumor marker in patients with esophageal carcinoma. Cancer Lett 205: 207-214, 2004.

11. Thong-Ngam D, Tangkijvanich P, Lerknimitr R, Mahachai V, Theamboonlers A and Poovorawan Y: Diagnostic role of serum interleukin-18 in gastric cancer patients. World J Gastroenterol 12: 4473-4477, 2006.

12. Smith DE: The biological paths of IL-1 family members IL-18 and IL-33. J Leukoc Biol 89: 383-392, 2011.

13. Moussion C, Ortega N and Girard JP: The IL-1-like cytokine IL-33 is constitutively expressed in the nucleus of endothelial cells and epithelial cells in vivo: a novel 'alarmin'? PLoS One 3: e3331, 2008.
14. Sun P, Ben Q, Tu S, Dong W, Qi X and Wu Y: Serum interleukin-33 levels in patients with gastric cancer. Dig Dis Sci 56: 3596-3601, 2011.

15. Van Cutsem E, Moiseyenko VM, Tjulandin S, Majlis A, Constenla M, Boni C, Rodrigues A, Fodor M, Chao Y, Voznyi E, et al: Phase III study of docetaxel and cisplatin plus fluorouracil compared with cisplatin and fluorouracil as first-line therapy for advanced gastric cancer: a report of the V325 Study Group. J Clin Oncol 24: 4991-4997, 2006.

16. Suzukawa M, Koketsu R, Iikura M, Nakae S, Matsumoto K Nagase H, Saito H, Matsushima K, Ohta K, Yamamoto K and Yamaguchi M: Interleukin-33 enhances adhesion, CD11b expression and survival in human eosinophils. Lab Invest 88: 1245-1253, 2008.

17. Bianchetti L, Marini MA, Isgrò M, Bellini A, Schmidt M and Mattoli S: IL-33 promotes the migration and proliferation of circulating fibrocytes from patients with allergen-exacerbated asthma. Biochem Biophys Res Commun 426: 116-121, 2012.

18. De Vita F, Giuliani F, Silvestris N, Catalano G, Ciardiello F and Orditura M: Human epidermal growth factor receptor 2 (HER2) in gastric cancer: a new therapeutic target. Cancer Treat Rev 36 (Suppl 3): S11-S15, 2010.

19. Xu Y, Huang S, Liu ZG and Han J: Poly(ADP-ribose) polymerase-1 signaling to mitochondria in necrotic cell death requires RIP1/TRAF2-mediated JNK1 activation. J Biol Chem 281: 8788-8795, 2006.

20. Wu T, Wang Z, Liu Y, Mei Z, Wang G, Liang Z, Cui A, Hu X, Cui L, Yang Y and Liu CY: Interleukin 22 protects colorectal cancer cells from chemotherapy by activating the STAT3 pathway and inducing autocrine expression of interleukin 8. Clin Immunol 154: 116-126, 2014.

21. Bergis D, Kassis V, Ranglack A, Koeberle V, Piiper A, Kronenberger B, Zeuzem S, Waidmann O and Radeke HH: High serum levels of the interleukin-33 receptor soluble ST2 as a negative prognostic factor in hepatocellular carcinoma. Transl Oncol 6: 311-318, 2013.

22. Chackerian AA, Oldham ER, Murphy EE, Schmitz J, Pflanz S and Kastelein RA: IL-1 receptor accessory protein and ST2 comprise the IL-33 receptor complex. J Immunol 179: 2551-2555, 2007.

23. Sui X, Kong N, Ye L, Han W, Zhou J, Zhang Q, He C and Pan H: p38 and JNK MAPK pathways control the balance of apoptosis and autophagy in response to chemotherapeutic agents. Cancer Lett 344: 174-179, 2014.

24. Yuan L, Wang J, Xiao H, Wu W, Wang Y and Liu X: MAPK signaling pathways regulate mitochondrial-mediated apoptosis induced by isoorientin in human hepatoblastoma cancer cells. Food Chem Toxicol 53: 62-68, 2013.

25. Fan $\mathrm{M}$ and Chambers TC: Role of mitogen-activated protein kinases in the response of tumor cells to chemotherapy. Drug Resist Updat 4: 253-267, 2001.

26. Mansouri A, Ridgway LD, Korapati AL, Zhang Q, Tian L, Wang Y, Siddik ZH, Mills GB and Claret FX: Sustained activation of JNK/p38 MAPK pathways in response to cisplatin leads to Fas ligand induction and cell death in ovarian carcinoma cells. J Biol Chem 278: 19245-19256, 2003.

27. Davis RJ: Signal transduction by the JNK group of MAP kinases. Cell 103: 239-252, 2000.

28. Lee ER, Kim JY, Kang YJ, Ahn JY, Kim JH, Kim BW, Choi HY, Jeong MY and Cho SG: Interplay between PI3K/Akt and MAPK signaling pathways in DNA-damaging drug-induced apoptosis. Biochim Biophys Acta 1763: 958-968, 2006.

29. Kim J, Kim C, Kim TS, Bang SI, Yang Y, Park H and Cho D: IL-18 enhances thrombospondin-1 production in human gastric cancer via JNK pathway. Biochem Biophys Res Commun 344: 1284-1289, 2006.

30. Luan L, Zhao Y, Xu Z, Jiang G, Zhang X, Fan C, Liu D, Zhao H, $\mathrm{Xu} \mathrm{K}$, Wang $\mathrm{M}$, et al: Diversin increases the proliferation and invasion ability of non-small-cell lung cancer cells via JNK pathway. Cancer Lett 344: 232-238, 2014.

31. Fontana VA, Sanchez M, Cebral E and Calvo JC: Interleukin-1 beta regulates metalloproteinase activity and leptin secretion in a cytotrophoblast model. Biocell 34: 37-43, 2010.

32. Chen SF, Nieh S, Jao SW, Wu MZ, Liu CL, Chang YC and Lin YS: The paracrine effect of cancer-associated fibroblast-induced interleukin-33 regulates the invasiveness of head and neck squamous cell carcinoma. J Pathol 231: 180-189, 2013.

33. Jovanovic IP, Pejnovic NN, Radosavljevic GD, Pantic JM, Milovanovic MZ, Arsenijevic NN and Lukic ML: Interleukin-33/ ST2 axis promotes breast cancer growth and metastases by facilitating intratumoral accumulation of immunosuppressive and innate lymphoid cells. Int J Cancer 134: 1669-1682, 2014. 